\title{
AN OVERHEAD CUVETTE STIRRER FOR STUDYING ENZYMES ATTACHED TO MICROGRANULAR MATRICES
}

\author{
by \\ STEPHEN J. BAYNE \\ MARTIN OTTESEN \\ Carlsberg Laboratorium, Department of Chemistry \\ Gamle Carlsberg Vej 10 - DK-2500 Copenhagen, Valby
}

Key words: Cuvette stirrer, immobilised enzymes

\begin{abstract}
An overhead stirrer was constructed to maintain a homogeneous suspension, in a spectrophotometer cuvette, of microgranular celluloses used for enzyme immobilisation. The presence of limited amounts of the celluloses was shown to have no effect on the spectra of solutes.
\end{abstract}

Matrix-bound enzymes have been receiving much attention during the past decade (for a review, see (7)). Spectrophotometric determination of the activity of matrix-bound enzymes generally requires a modification of the corresponding free enzyme assay. In homogeneous catalysis, the rate of only a very few enzyme reactions is diffusion controlled; in heteroge- neous catalysis, however, the situation is different and the activity can only be estimated when some method has been found which minimises the diffusion layer around the surface of the matrix. HORNBY et al. (4) achieved this by continuous stirring of the immobilised enzyme suspension and the spectrophotometric measurements were performed on small aliquots of 
the filtered solution. LILLY et al. (5) passed substrate over a column of the immobilised enzyme and measured the activity in the eluant spectrophotometrically.

The direct assay of immobilised enzymes by continuous spectrophotometry has generally been avoided because it was feared that the suspension of matrix particles would distort the absorbancy measurements of the enzyme activity. However, MORT et al. (6), PREUVENEERS et al. (8) and WeLiky et al. (9) have carried out immobilised enzyme assays by direct spectrophotometric measurement of the stirred enzyme suspension in the cuvette. In all of these reports, a small magnet was used in the cuvette to maintain a homogeneous distribution of the immobilised enzyme.

An alternative method of maintaining this homogeneous distribution is to stir the cuvette suspension by a small overhead paddle. HERLITHY and MURPHY (3) have used a microstirrer to follow the super-precipitation of actomyosin. The present report describes the design

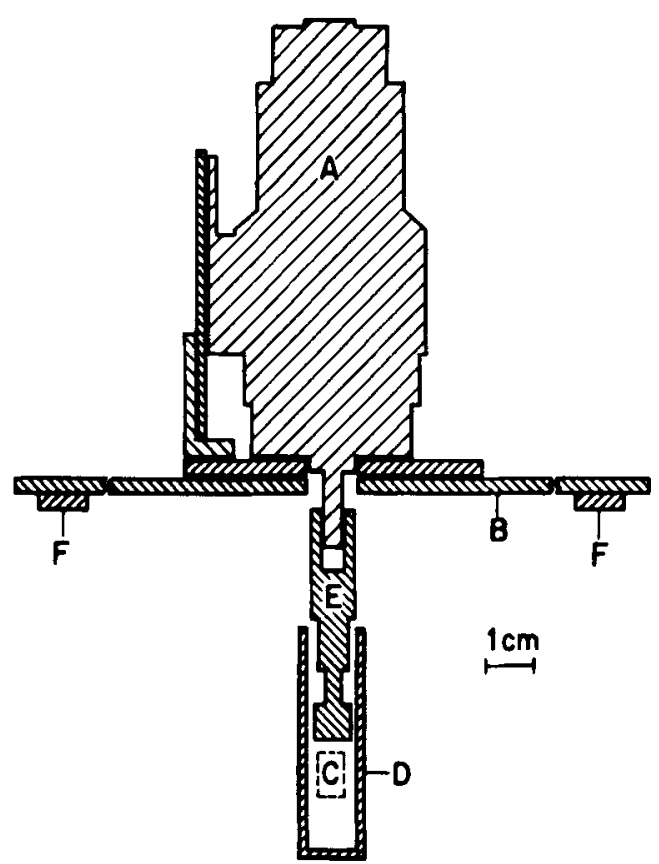

Figure 1.

A. Diagram showing the relative positions of the stirrer motor, lightpath and cuvette. A, Stirrer motor; B, baseplate; C, spectrophotometer lightpath; D, $10 \mathrm{~mm}$ cuvette; $\mathrm{E}$, teflon paddle; $\mathrm{F}$, positioning stops for the baseplate. of a similar overhead cuvette stirrer which has been used to study the stability and kinetic properties of three dehydrogenases covalently attached to microgranular aminoethylcellulose (2).

The detail of the cuvette assembly is shown in Figs. 1A and 1B. The stirrer, obtainable from Meccano or Fleischmann, was a 6-volt d.c. electric motor with an output axle speed of $300 \mathrm{rev} . / \mathrm{min}$. This output speed was found to be most efficient for maintaining a homogeneous distribution of the immobilised enzyme. No sedimentation occurred and the magnetic field of the motor had only negligible effect on the electronic circuitry of the spectrophotometers used.

The presence of Cellex-AE (microgranular aminoethylcellulose) in the cuvette naturally may cause higher apparent absorbancy readings owing to the light scattering. It is therefore of importance to establish whether a Beer's law relationship is valid for a solute in the presence of Cellex-AE. It must also be established whether the presence of Cellex-AE causes a distortion in the solute spectrum. For thus purpose, the solute chosen was myoglobin which has both a Soret band at $408 \mathrm{~nm}$ (1) as well as a pro-

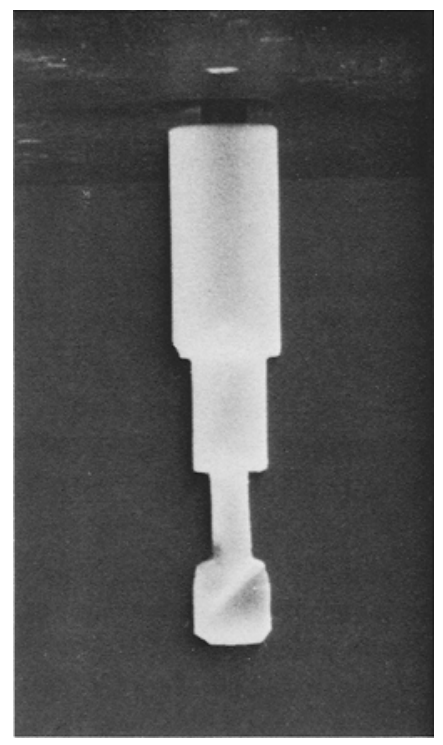

B. Enlarged detail of E, showing the screw nature of the teflon paddle which maintains the homogeneous suspension of matrix in the cuvette. 


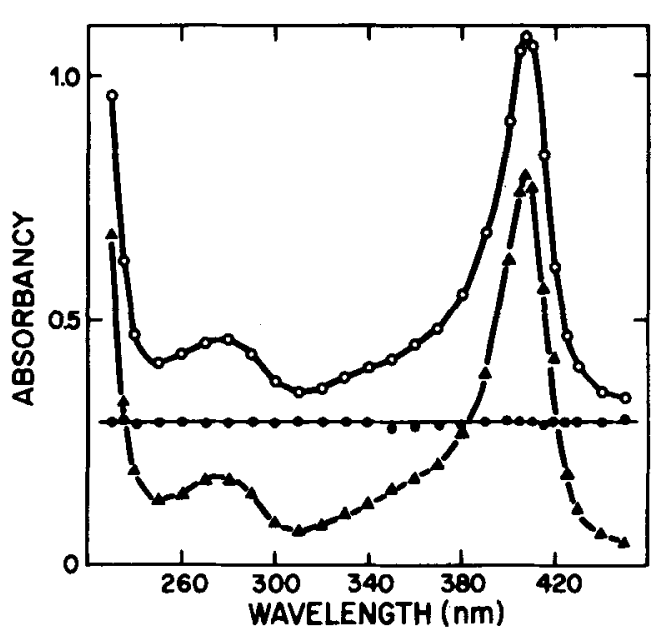

Figure 2. Spectrum of myoglobin in the presence and absence of Cellex-AE. The spectrum of myoglobin was obtained in the presence $(O-O)$ and absence (^-A) of Cellex-AE $(0.74 \mathrm{mg} / \mathrm{ml})$ in the range $450-230 \mathrm{~nm}$. The difference curve (- $)$ is a straight line which reflects the absorbance owing to Cellex-AE in the same spectral range.

tein absorption peak at $280 \mathrm{~nm}$. The buffer used in all optical studies was $0.1 \mathrm{M}$-potassium phosphate, $\mathrm{pH} 7,4$.

The spectrum of myoglobin in the presence and absence of Cellex-AE is shown in Fig. 2. The straight line obtained from the difference of the two spectra shows that the spectrum of myoglobin is not influenced by the presence of Cellex-AE in the spectral range studied.

The effect of varying the myoglobin concentration in the presence of various amounts of Cellex-AE is shown in Fig. 3. As the slopes are parallel within a $2 \%$ error, increasing the concentration of Cellex-AE has no effect on the absorbance of myoglobin at $230 \mathrm{~nm}$, apart from the expected increase owing to the presence of Cellex-AE. The absorbance of Cellex-AE was linearly dependent on its concentration up to a concentration of $1.5 \mathrm{mg} / \mathrm{ml}$ in the cuvette. For the study of immobilised dehydrogenases, the maximum concentration of Cellex-AE used in kinetic and stability studies was $1.0 \mathrm{mg} / \mathrm{ml}$.

The presence of Cellex-AE has similarly no effect on the rate of reduction of $\mathrm{NAD}^{+}$by various amounts of yeast alcohol dehydrogenase (Fig. 4).

The results presented in this report show that the presence of Cellex-AE in a cuvette has no

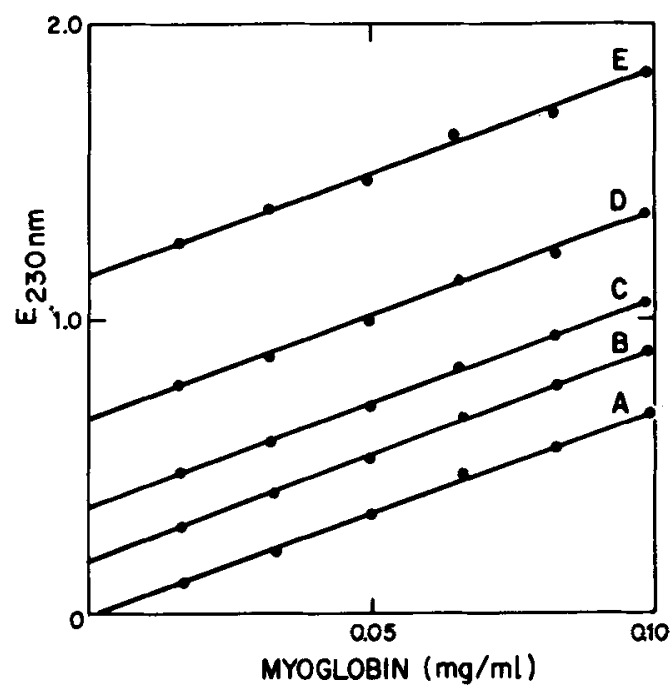

Figure 3. Effect of various Cellex-AE concentrations on the absorbance of various myoglobin concentrations.

The absorbance of six different myoglobin concentrations were measured at $230 \mathrm{~nm}$ in the presence of various amounts of Cellex-AE. A, no Cellex-AE; B, 0.37 $\mathrm{mg} / \mathrm{ml} ; \mathrm{C}, 0.74 \mathrm{mg} / \mathrm{ml} ; \mathrm{D}, 1.48 \mathrm{mg} / \mathrm{ml} ; \mathrm{E}, 2.96 \mathrm{mg} / \mathrm{ml}$. The plots, obtained from linear regression formula, were parallel within a $2 \%$ error.

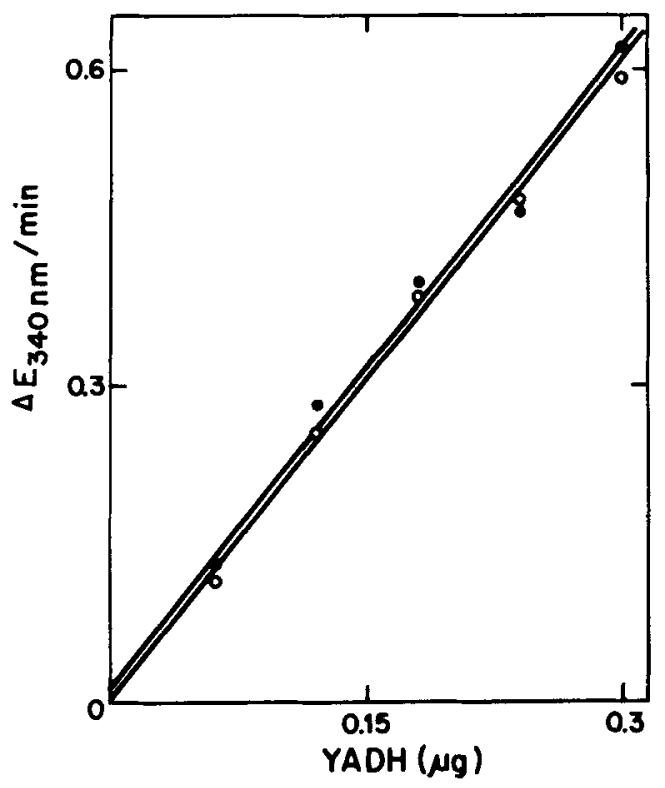

Figure 4. Effect of Cellex-AE on the rate of $\mathrm{NAD}^{+}$reduction by various amounts of yeast alcohol dehydrogenase. Yeast alcohol dehydrogenase (YADH) was assayed in $3.2 \mathrm{ml} 50 \mathrm{~mm}$-sodium pyrophosphate buffer, $\mathrm{pH} 8.4$, containing $0.9 \mathrm{~mm}-\mathrm{NAD}$ and 700 mM-ethanol. Assays were initiated by the addition of enzyme. Rates were measured at $25^{\circ} \mathrm{C}$ in the presence $(\mathrm{O}-\mathrm{O})$ and absence $(\bullet-\bullet)$ of Cellex-AE. 
effect on the spectrum of a solute or on the rate of an enzymic reaction. They also show that the stirrer is capable of maintaining a homogeneous suspension of insoluble matrix.

\section{ACKNOWLEDGEMENTS}

One of us (S. J. B.) would like to thank Dr. W. E. HORNBY for his advice throughout the early stages of this work, as well as gratefully acknowledge the financial support of the S. R. C. and the Carlsberg Laboratory. S. J. B. would also like to thank HELMUTH CHRISTENSEN for the design of the stirrer baseplate for use in conjunction with a Cary 118 spectrophotometer and the entire Department of Chemistry staff who suffered him silently during his stay at the Carlsberg Laboratorium.

\section{REFERENCES}

1. Abrash, H. I.: The hydrogen-deuterium exchange of native and acid denatured sperm whale myoglobin. Compt. Rend. Trav. Lab. Carlsberg 37: 107-128 (1970)

2. BAYNE, S. J.: Some studies on soluble and immobilised dehydrogenases. Ph. D. Thesis (St. Andrews, Scotland) (1974)
3. Herlithy, J. T. \& R. A. Murphy: A versatile, inexpensive microstirrer for spectrophotometer cuvettes. Anal. Biochem. 41: 290-291 (1971)

4. Horndy, W. E., M. D. Lilly \& E. M. CROoK: Preparation and properties of ficin chemically attached to carboxymethylcellulose. Biochem.J. 98: 420-425 (1966)

5. Lilly, M. D., W. E. Hornay \& E. M. Crook: The kinetics of carboxymethylcellulose-ficin in packed beds. Biochem.J. 100: 718-723 (1966)

6. Mort, J. S., D. K. K. Chong \& W. W. -C. Chan: Continuous spectrophotometric assay of a Sepharose-bound enzyme and its use to study kinetics of coupling of the enzyme to Sepharose. Anal. Biochem.52: 162-168 (1973)

7. Mosbach, K.: Immobilised enzymes. In: H. Gutfreund, ed., Enzymes: One Hundred Years, F.E.B.S. Lett. pp. E 80-E 95 (1976)

8. Preuveneers, M. J., D. Peacock, E. M. Crook, J. B. Clark \& K. Brocklehurst: D-3-hydroxybutyrate dehydrogenase from Rhodopseudomonas spheroides. Kinetic mechanism from steady-state kinetics of the reaction catalysed by the enzyme in solution and covalently attached to diethylaminoethylcellulose. Biochem. J. 133; 133-157 (1973)

9. Weliky, N., F. S. Brown \& E. C. Dale: Carrier-bound proteins: properties of peroxidase bound to insoluble carboxymethylcellulose particles. Arch. Biochem. Biophys. 131: 1-8 (1969) 